\title{
Experimental Study of the Effect of Continuous Surfactant Injection Alternating Cyclic Huff \& Puff Stimulation on Oil Efficiency Recovery in A 3D Reservoir Physical Model
}

\author{
David Maurich ${ }^{1}$ \\ Petroleum Engineering Study Program, Faculty of Engineering \& Design, ITSB, Bekasi, Indonesia \\ E-mail: davidmaurich@gmail.com
}

Informasi naskah:

Diterima

29 Mei 2019

Direvisi

00 Juni 2019

Disetujui terbit

00 Juli 2019

Diterbitkan

00 Agustus 2019

\begin{abstract}
Surfactant can displace oil which trapped by capillary effect, make it easier to be produced and finally improve oil recovery factor. However, the effectiveness of surfactant injection depends on many parameters such as surfactant-reservoir fluids properties and interaction, reservoir characteristics and its interaction with surfactant and also surfactant injection scenario or operational methods. This paper discusses about the effect of continuous surfactant injection alternating huff \& puff stimulation on oil recovery factor from a quadrant of five-spot pattern in a 3D physical model made from a mixture of sands, cement and water with dimension of $15 \mathrm{~cm} \mathrm{x} 15 \mathrm{~cm} \times 2.5 \mathrm{~cm}$ to serve as the surrogate for oil reservoir in laboratory. In order to simulate the oil recovery from a secondary waterflooding process, $0.17 \mathrm{PV}$ of formation water was injected into 3D reservoir physical model. This process could recover about $25.5 \%$ OOIP from the physical model, however the injection then shortly terminated due to a drastically increase of watercut. Residual oil then be recovered by a sequence of continuous surfactant injection alternating huff and puff stimulation method. The recovery factor by continuous surfactant injection combine with chase water drive gave a $5.5 \%$ OOIP additional recovery and another $6.8 \%$ OOIP after 24 hours surfactant huff $\&$ puff stimulation in the first sequence. After conducting 3 series of a combination of continuous surfactant injection alternating huff \& puff stimulation, the total oil recovery from overall processes was about $51.7 \%$ OOIP. We presume that the lack of mobility control on macroscopic sweep efficiency in a 3D reservoir physical model is the rationale behind this moderate oil recovery which only produced by surfactant microscopic displacement efficiency. Nevertheless, the research shows that the combination of continuous surfactant injection alternating huff \& puff stimulation obviously improve the recovery factor to some extent.
\end{abstract}

Keywords: $3 D$ reservoir physical model, continuous surfactant injection, huff and puff method, recovery factor, water flood 


\section{INTRODUCTION}

At the present time, the injection of water into the reservoir after primary recovery is the most commonly used method of displacing the oil left in rock formations. However, ordinary waterflood is physically incapable of displacing all the oil (non-wetting phase) from reservoir rock. The competition between the capillary forces and viscous forces acting during the waterflood may cause part of the oil to be retained, in water-wet rock at least, as disconnected structures which do not flow (trapped) under the pressure gradient that arises from the flow of the water.

This capillary forces cause the residual oil saturation " $S_{\text {or }}$ " which can range typically from 15 to $40 \%$ of pore space, will be retained. The residual oil saturation after waterflooding strongly water wet rocks at normal rates depends on the initial water saturation and the pore geometry. This trapped residual oil cannot be recovered and displaced until a critical value of interfacial tension has been reached ${ }^{9)}$. Thus this residual oil saturation becomes an important target for tertiary recovery or commonly known as Enhanced Oil Recovery. Enhanced oil recovery is a process include injection one or several fluids into reservoir to increase natural drive which the injected fluid will be interact to oil, brine, and rock, and create a condition to maximize recovery factor. The condition is reducing interfacial tension, change the rock wettability, increase oil volume, reduce oil viscosity, and good fluid behavior ${ }^{2)}$.

The effect of capillary forces into trapping oil in microscopic pores is shown in dimensionless parameter called capillary number. A capillary number $\left(N_{c a}\right)$ is a ratio between viscous forces and capillary forces.

$$
N_{c a}=\frac{\text { Viscous Forces }}{\text { Capillary Forces }}=\frac{v \times \mu_{w}}{\sigma_{o w}}
$$

where,

$N_{c a}=$ Capillary Number

$v=$ Average velocity of fluid in the pores $(f t / D)$

$\mu_{w}=$ Displacing fluid vis $\cos$ ity $(c P)$

$\sigma_{o w}=$ Interfacial Tension $(I F T)$ between water and oil (dyne $\left./ \mathrm{cm}\right)$

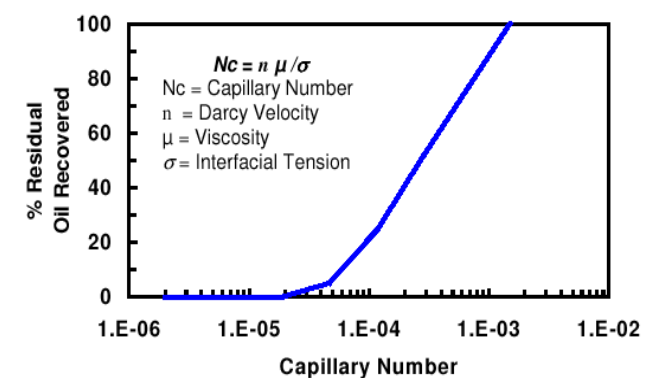

Figure 1. Capillary Number and Recovery Factor Curve ${ }^{2)}$ 
Based on the relationship between capillary number and recovery factor (as shown in Figure 1), it shows that increasing oil recovery can be achieved by maximizing capillary number ${ }^{4)}$. Therefore, in this research we proposed to decrease the interfacial tension between the water and oil by introducing surfactant which already proven as one of the most promisable and widely used in the oil field for chemical EOR projects. Moreover, surfactant can mobilize the trapped oil and make it to be possible produced with a small energy and this condition in fact, directly improve oil recovery factor.Surfactant was known as wetting agent, an active agent that, when present at low concentration in a system, has the property of adsorbing onto the surfaces or interfaces of the system and of altering to a marked degree the surface or interfacial free energies of those surfaces ${ }^{6}$. Wetting means fluid coats solid surface and non-wetting means fluid usually left from solid surface. Surfactant usually was organic compound which hydrophobic means dislike water but soluble in oil on the tail and hydrophilic means like water and soluble in water on the head. Therefore, surfactant was semi soluble in water or in organic compound. It makes surfactant is effective and efficient to be used in EOR process because can mobilize residual oil in pores of reservoir rock so it was easy to flow. However, the microscopic displacement efficiency of surfactant and its ability to displace the trapped oil in microscopic pore spaces depends on some parameters such as; pore geometry, interfacial tension, wettability and contact angle, differential pressure $(\Delta \mathrm{P})$ or gradient of pressure $(\Delta \mathrm{P} / \mathrm{L})$, characteristic chromatography movement of surfactant in a particular system and reservoir heterogeneities.

Additionally, the reduction of interfacial tension conjunction with capillary pressure, wettability alteration and the extent of swept area is much rely on the surfactant type, concentration and exposure time between the surfactant and reservoir fluids and rocks. In a continuous surfactant injection, particularly when the breakthrough time has reached and beyond, the effectiveness and the microscopic displacement efficiency of surfactant injection rate would slowly diminish along with time and more watercut will be observed in production well. In order to resolve this issue, this research proposed an alternative solution by conducting a combination of continuous surfactant injection alternating huff \& puff stimulation method. 


\section{METHODOLOGY}

Below is depicted the methodology used in this research which is notably performed through an extensive laboratory investigation (experimental study).

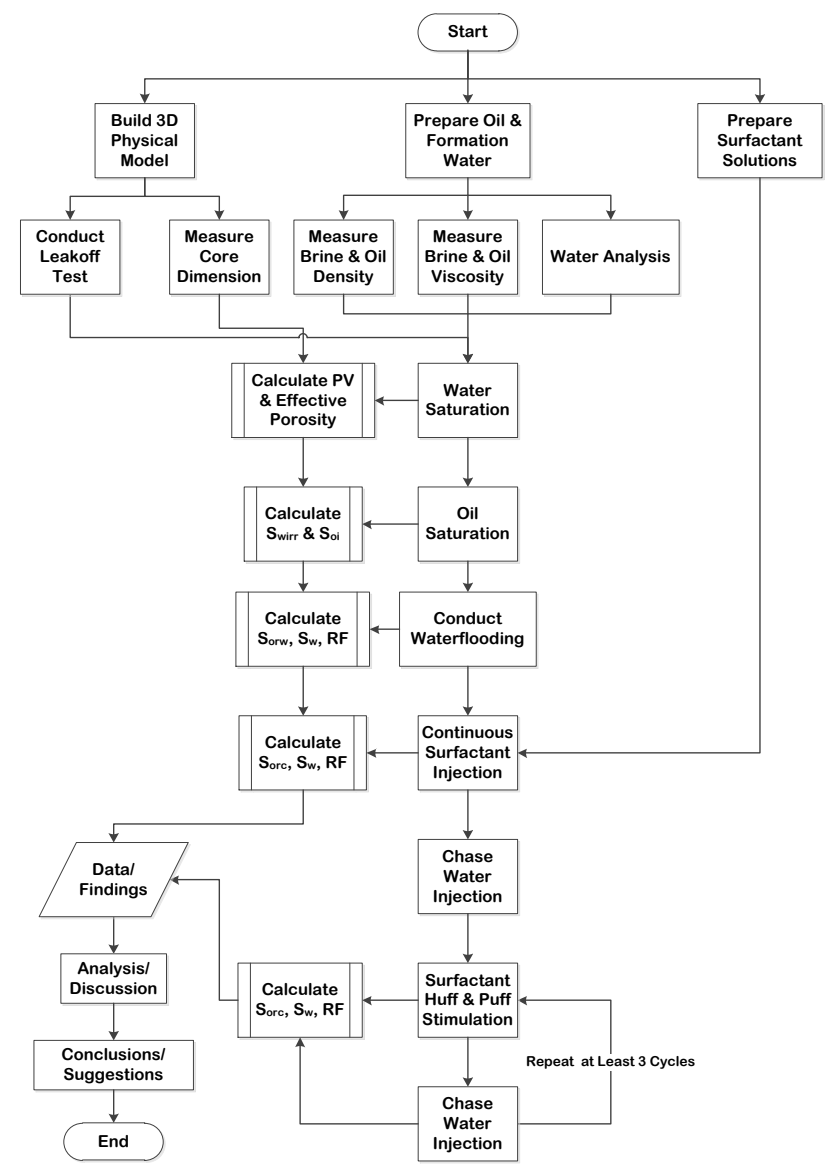

Figure 2. Research methodology.

\subsection{Equipment}

3D reservoir physical model, sieve analysis apparatus, digital balance, temperaturecontrolled air bath (oven), vacuum pump, Ruska constant rate injection pump, multifunction chambers, compressor, hot plate magnetic stirrer, and picnometer.

\subsection{Materials}

Sands, cement, water, oil sample \& brine from field-X, surfactant (active content 99\%), toluene, stainless steel tubing 1/16 in, valves, filter papers, and epoxy resin $\&$ hardener.

\subsection{Preparation and Experimental Procedures}

3D physical model is used for simulating oil recovery processes through a 5-spot injection pattern in laboratory. Description of the model is depicted in Figure 3 and Figure 5 . 

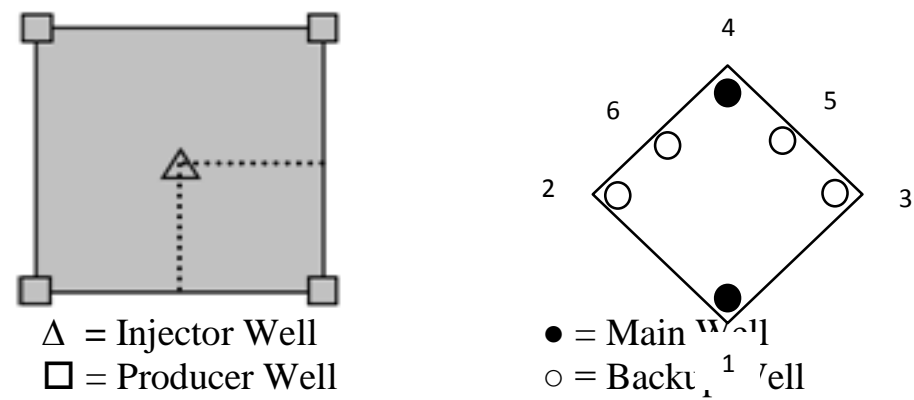

Figure 3. Well position at a quadrant of inverted five-spot injection pattern.

The physical model was made of quartz sands with dimension of $15 \mathrm{~cm} \times 15 \mathrm{~cm} \times 2.5$ $\mathrm{cm}$, and used as the artificial oil reservoir. The use of this 3D model is more reliable and widely acceptable to represent oil reservoir in laboratory comparing to one-dimensional core sample since the effect of sweep macroscopic efficiency and microscopic displacement efficiency could be observed and determined experimentally. Meanwhile, the process of the oil and water phase interaction and flowing in porous media was observed and also recorded using high resolution camera recorder.

Before using the 3D physical model for testing, a leak off test was conducted to ensure the model is fully isolated and well coated by epoxy. Once model has been tested, the air in pore spaces is evacuated using vacuum pump and then saturated with formation water until it was fully water saturated. The back-up wells used to support the saturation process and to maximize the saturation area in all pore spaces of the model. By subtracting the weight of the saturated model with its dry weight, the pore volume and the porosity of the model then can be calculated. In order to simulate the oil migration process in the reservoir, amount of oil is injected to displace water phase until its irreducible water saturation condition achieved. Hence, a 3D physical model has become a representative of reservoir in laboratory and ready for recovery process scenarios.

Table 1 . The initial condition of 3D reservoir physical model.

\begin{tabular}{llllll}
\hline Parameter & Value & Unit & Parameter & Value & Unit \\
\hline Length $(\mathrm{L})$ & 15 & $\mathrm{~cm}$ & Porosity $(\varnothing)$ & 18.86 & $\%$ \\
Width $(\mathrm{W})$ & 15 & $\mathrm{~cm}$ & Oil Saturation $\left(\mathrm{S}_{\mathrm{oi}}\right)$ & 63.33 & $\%$ \\
Thickness $(\mathrm{T})$ & 2.5 & $\mathrm{~cm}$ & Water Saturation $\left(\mathrm{S}_{\text {wirr }}\right)$ & 36.67 & $\%$ \\
Pore Volume $(\mathrm{PV})$ & 106.08 & $\mathrm{~cm}^{3}$ & & & \\
\hline
\end{tabular}

\section{RESULTS AND DISCUSSION}

\subsection{Formation Water}

Formation water from field-X was used as diluting fluid in making surfactant injection solution. Indigenous formation water is more favorable comparing with other surface water because it's compatibility with the reservoir fluid and rocks. Based on the water analysis testing conducted by FTSL water quality laboratory ITB on this formation water, the 
salinity of brine was about 13133.62 ppm. Salinity is crucial due to its adverse effects on surfactant performance, since increasing salinity of an aqueous phase will decrease the solubility of an ionic surfactant and may cause severe salt precipitation. High salinity formation water can also plug some reservoir pore spaces and significantly reduces its effective permeability.

Table 2. Water analysis data of field-X.

\begin{tabular}{llllllll}
\hline No. & Parameters & Value & Unit & No. & Parameters & Value & Unit \\
\hline 1 & TDS & 18650 & ppm & 6 & Potassium $\left(\mathrm{K}^{+}\right)$ & 163.21 & $\mathrm{ppm}$ \\
2 & Hardness $\left(\mathrm{CaCO}_{3}\right)^{*}$ & 213.6 & ppm & 7 & Bicarbonate $\left(\mathrm{HCO}_{3}{ }^{-}\right)$ & 3795 & $\mathrm{ppm}$ \\
3 & Calcium $\left(\mathrm{Ca}^{2+}\right)$ & 46.81 & ppm & 8 & Sulfate $\left(\mathrm{SO}_{4}{ }^{2-}\right)$ & 379.3 & $\mathrm{ppm}$ \\
4 & Magnesium $\left(\mathrm{Mg}^{2+}\right)$ & 23.53 & ppm & 9 & Chloride $\left(\mathrm{Cl}^{-}\right)$ & 7270 & $\mathrm{ppm}$ \\
5 & Sodium $\left(\mathrm{Na}^{+}\right)$ & 6184 & ppm & 10 & $\mathrm{CO}_{2}$ Total & 0 & $\mathrm{ppm}$ \\
\hline & Salinity & \multicolumn{3}{c}{13133.62} & & \multicolumn{3}{c}{$\mathrm{ppm}$} \\
\hline
\end{tabular}

\subsection{Fluid Density and Viscosity}

The density and viscosity of each fluid in this research have been measured in room temperature condition $\left(26{ }^{\circ} \mathrm{C}\right)$ using picnometer and Ostwald viscometer, respectively. Based on data in Table 3, it shows that density of formation water of field-X is higher than oil-X, however the formation water viscosity is lower than the oil viscosity. This result confirm that the viscosity ratio between the displaced fluid phase over displacing fluid phase is about 1.47 (more than unity) that could lead to unstable displacement process.

Table 3. Density and viscosity data of field-X.

\begin{tabular}{llll}
\hline No. & Fluid & Density (gr/cc) & Viscosity (cp) \\
\hline 1 & Brine-X & 1.015 & 0.960 \\
2 & Oil-X & 0.807 & 1.409 \\
\hline
\end{tabular}

\subsection{Displacement Tests and Recovery Processes}

In order to recover oil from 3D physical model, we performed two different recovery methods to simulate primary, secondary and tertiary recovery in the actual field condition. For primary and secondary recovery method in laboratory, $0.17 \mathrm{PV}$ of formation water injected into the model continuously using 1000 cc Ruska positive displacement pump at a rate of $0.273 \mathrm{cc} / \mathrm{min}$ (equivalent to $2.5 \mathrm{ft} /$ day in a field condition). It will be necessary to adapt injection rate in laboratory with a typical field condition. Theoretically, a good displacement process in a reservoir condition will be attained at injection rate of 1-3 ft/day.

The first water breakthrough was observed at $0.14 \mathrm{PV}$ water injection. The result showed a significant oil recovery from the model, where the final tally of oil recovery factor after waterflood was about 25.5\% of OOIP (see Figure 6 and Table 4). However, the displacement process still left about $47.16 \% \mathrm{PV}$ of oil as residual oil saturation $\left(\mathrm{S}_{\text {orw }}\right)$ in the microscopic pore spaces of model. Amount of water injected later would not be effective to displace oil from the reservoir model particularly when breakthrough time has been reached, in reverse, watercut drastically increase along with quantity of water injected in the secondary recovery process due to the competition of viscosity and capillary forces 
during the displacement process. Therefore, the waterflooding then shortly terminated. These trapped oil will require a very high pressure usually exceeds the formation fracture gradient. Thus, almost impossible to recover the oil by ordinary waterflooding method, unless the critical value of IFTs between the water and oil has been reached (the IFT reduction). In this research, this residual oil saturation of proven accessibility with respect to injected fluids is an important target for tertiary recovery using surfactant injection.

In the tertiary recovery process using surfactant injection, a combination of injection method between continuous injection and cyclic huff $\&$ puff stimulation was conducted in series. The first stage in the whole tertiary processes was injecting surfactant continuously with $0.218 \mathrm{cc} / \mathrm{min}$ injection rate which is equivalent to $2 \mathrm{ft} / \mathrm{d}$ in actual field condition. This injection rate was adjusted slower than injection rate applied to the water injection process. By using slower injection rate we expected surfactant has a great opportunity and possibility to react with reservoir fluids and rocks to create a good stable front during the displacement process in reservoir pore spaces. This condition will give a lot of chances to surfactant monomers to reduce the fluids interfacial tension and capillary forces and then promote the reduction of residual oil saturation and maximize the oil recovery factor. In this stage, surfactant was continuously injected into the injector well at $0.2 \mathrm{PV}$ with a concentration of $2 \mathrm{wt} \%$ followed by $0.36 \mathrm{PV}$ of chase water injection at a rate of 0.273 $\mathrm{cc} / \mathrm{min}$ as a driving water phase to give a sufficient supporting energy in the displacement process. These two processes gave a significant additional to the oil recovery factor to 5.5 $\%$ of OOIP. As the result, the cumulative oil recovery increase to $31 \%$ of OOIP (see Figure 6 and Figure 7). Since the watercut was drastically increase to $98.21 \%$, therefore the chase water injection process was then terminated.

The ineffective recovery process was directly correlated with the quantity of the mobile oil in the rock pore spaces. When surfactant contact with the trapped oil due to the capillary and viscosity forces competition, monomers of surfactant will spontaneously absorbed into the fluids and rock interfaces and reduce the interfacial tension significantly to the lowest value, this process allows the trapped oil to become mobile and easily to be displaced and produced. The driving water in the rear front will assist the displacement and recovery process and allows oil to be produced through the producer well. Once mobile oils have been produced, the chase water injection would not be effective anymore. The rest of oil left in microscopic pore spaces are in trapped situation and have high capillary forces. This recovery mechanism is usually known as stripping process.

In order to resolve this problem and recover the residual oil in such situation, farther critical value of interfacial tension must be reached to make the trapped oil become mobile. Hence, amount of surfactant is required to be injected again hoping to promote lower interfacial tension. Lower interfacial tension could be achieved by injecting higher concentration surfactant which deemed too costly. Other more practical solution is soaking the reservoir by the same concentration of surfactant and let it react longer with the reservoir fluids and rocks to create a maximum IFTs reduction. This condition will be 
achieved only by performing huff \& puff process (see Figure 4). In this research we conducted three cycles of surfactant huff \& puff processes (see Figure 7). Each cycle required $0.2 \mathrm{PV}$ of surfactant injection at a concentration of $2 \mathrm{wt} \%$. After the injection was stopped, the injector and producer wells were shut and let the surfactant stayed in the reservoir for various soaking time (e.g., 24 hours and 35 hours). The recovery process was then performed by injecting chase water until a $99 \%$ of water cut reached.

In the first cycle of surfactant huff \& puff stimulation, surfactant was allowed to react with reservoir fluids and rock for 24 hours of soaking time. As a result, $6.8 \%$ OOIP of incremental oil was successfully recovered from the physical model. This gain brought a total recovery factor to $37.8 \%$ OOIP (see Figure 6 and Figure 7). Since the watercut has reached $99.07 \%$, the injection of chase water was then terminated.

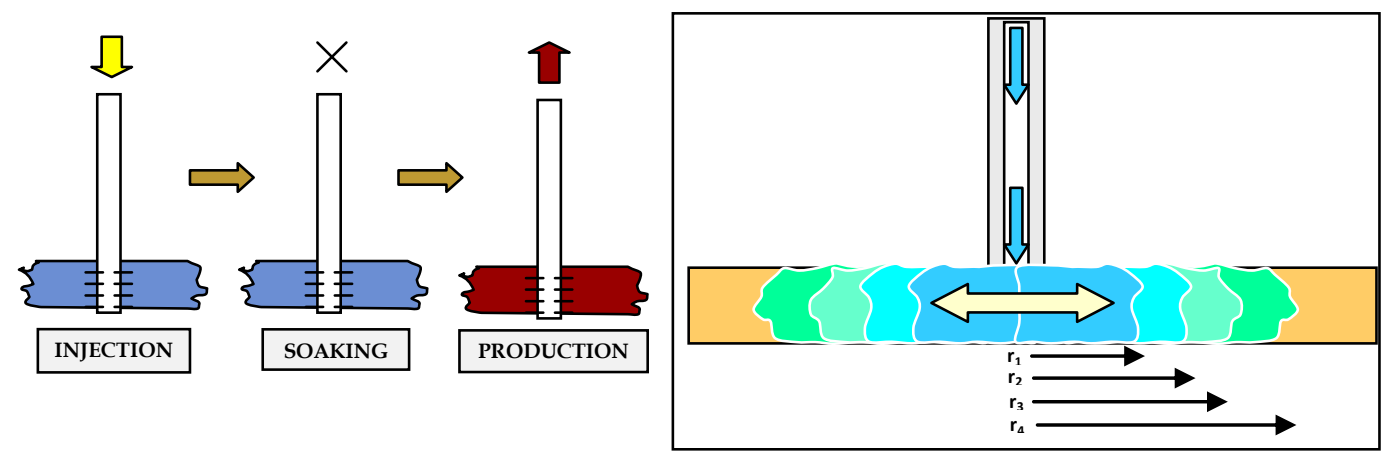

Figure 4. The effect of soaking time to surfactant invasion area and reaction time in a surfactant stimulation process with huff \& puff metode.

Figure 5 shows a shadowgraph for flood progress with a maroon elliptical shaped area which is considered as easier EOR target to be swept by displacing fluid phase than other region of model. After the waterflooding process, the amount of residual oil saturation in this region is usually lower than outside of the region. The residual oil will strongly depend on the competition among the viscous force, gravity force and capillary force acting during the flood progress. That's why the recovery process and gain for this flooded region (particularly after waterflooding breakthrough) would be difficult even for continuous surfactant injection. Generally, surfactant injection later after water breakthrough will follow the water paths in microscopic pore spaces which lead to a poor macroscopic swept efficiency. This research proposes the combination of continuous surfactant injection with cyclic huff \& puff stimulation as a feasible solution for residual oil recovery in a waterflooded reservoir. In the concept of surfactant stimulation, the monomers of surfactant will have sufficient time to interact and react with the residual oils, formation water and rock (reduce IFTs) both in the flooded zone and unflooded zone which in the end will develop broader volumetric sweep in the physical model (through stripping recovery process). 

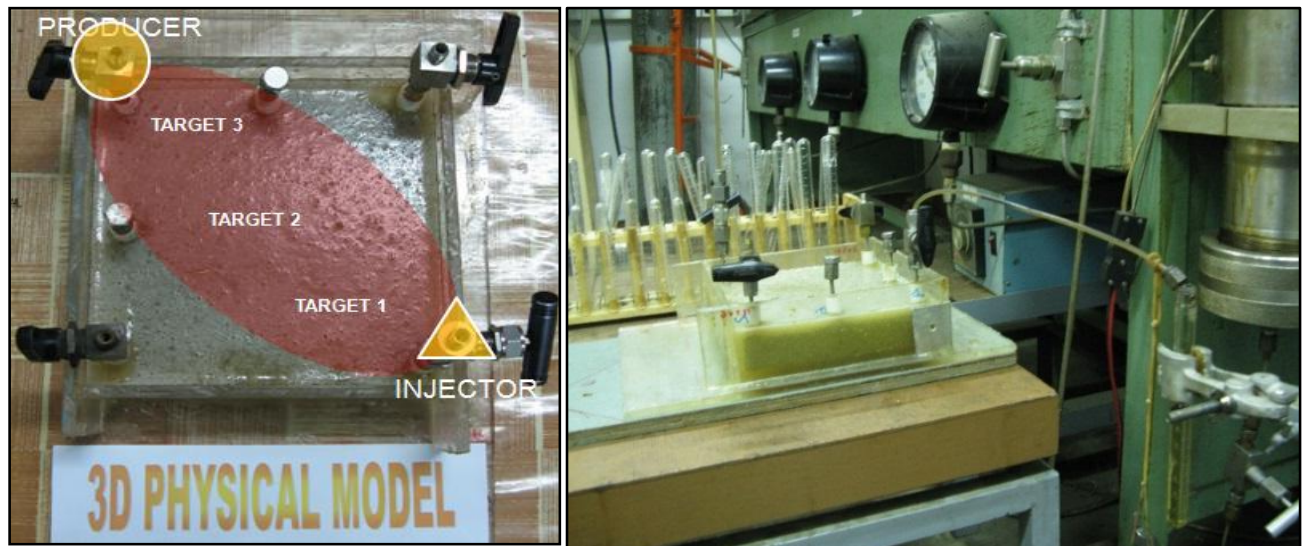

Figure 5. Well position, shadowgraph for flood progress and experimental setup for waterflooding and surfactant injection in 3D physical model.

In the second cycle of surfactant stimulation process, $0.2 \mathrm{PV}$ of surfactant injection at a concentration of $2 \mathrm{wt} \%$ was re-injected into the injector well of the physical model. After 24 hours soaking time, the residual oils become mobile oils and were then produced by injected 1.56 PV of chase water at a rate of $0.273 \mathrm{cc} / \mathrm{min}$ as a driving force to give sufficient supporting energy during the displacement and recovery process. Once the watercut has reached $99.47 \%$, then the chase water injection was terminated. The result of this process brought $6.9 \%$ OOIP of additional oil recovery to the previous processes. Hence, the total oil recovery after the second cycle of surfactant stimulation becomes 44.7 $\%$ OOIP.

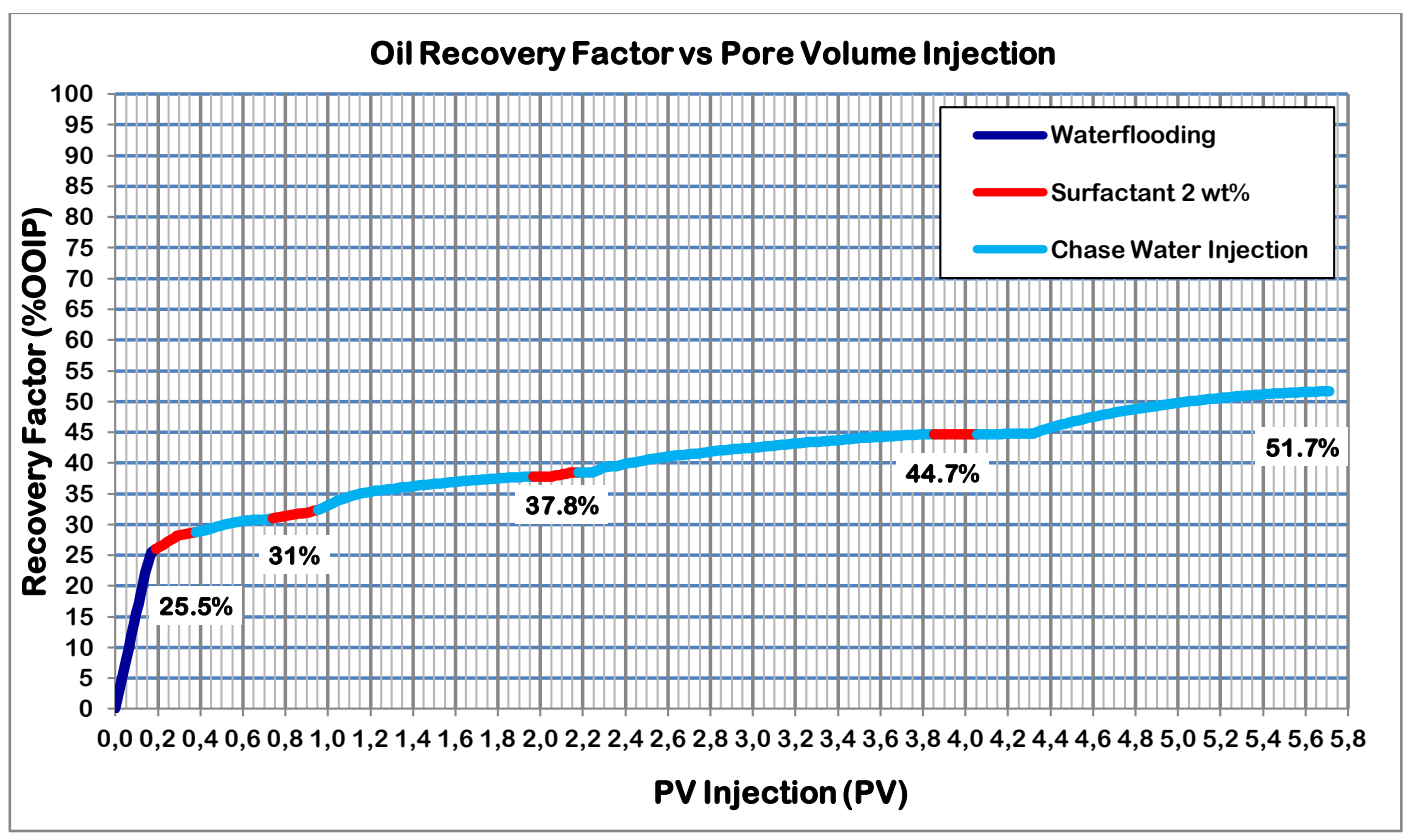

Figure 6. Oil recovery factor as function of pore volume injection (PVI). 
With there were still a lot of oil left in microscopic pore spaces of model after the second surfactant stimulation, we then proposed to conduct the third cycle of surfactant huff \& puff stimulation. The amount of surfactant and its concentration were referred to the previous stimulations. However, the soaking time was extended longer to 84 hours or 3.5 days to allow a maximum IFTs reduction by surfactant monomers. After injecting 1.39 PV of chase water with a rate of $0.273 \mathrm{cc} / \mathrm{min}$ to displace the mobile oils to producer well, this process bring $7 \%$ OOIP additional oil recovery. Consequently, the total oil recovery factor for the whole recovery processes in the 3D physical model increase to $51.7 \%$ OOIP. Although the possibility to increase the total oil recovery factor is high by conducting the next stimulation cycle, we decided not to proceed with the idea because of other technical reasons.

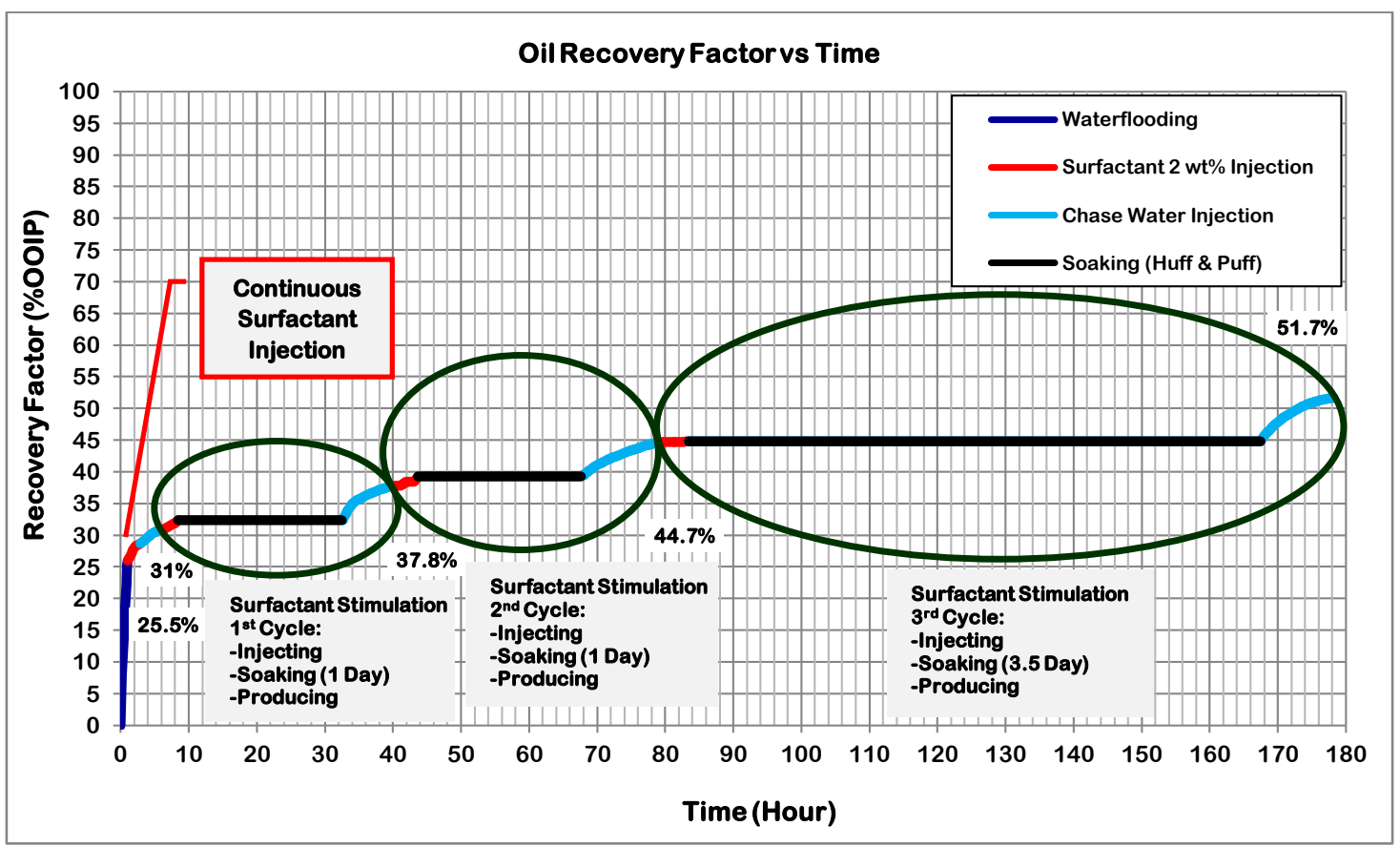

Figure 7. Oil recovery factor as function of time.

Viscosity ratio between the displaced fluid phase over displacing fluid phase in this research is about 1.47 (more than unity), it means that recovery techniques in this model could be unfavorable due to unstable displacement process. We presume that macroscopic sweep efficiency is the major issue in 3D physical model recovery processes. Theoretically, the overall displacement efficiency $\left(E_{T}\right)$ in a process can be viewed conceptually as a product of the volumetric sweep $\left(E_{V}\right)$, and the microscopic displacement efficiency $\left(E_{D}\right)$. Volumetric sweep is a macroscopic efficiency defined as the fraction of reservoir (or project) PV invaded by the injected fluid, or stated another way, the fraction of PV that has been contacted or affected by the injected fluid.

$$
E_{T}=E_{V} \times E_{D}
$$


Mobility control is a generic term describing any process where an attempt is made to alter the relative rates at which injected and displaced fluids move through a reservoir. The objective of mobility control is to improve the volumetric sweep efficiency of a displacement process. Mobility control is usually discussed in terms of the mobility ratio $(M)$, and a displacement process is considered to have mobility control if $M \leq 1$. For a water-based immiscible displacement process, mobility ratio can be written in a mathematical expression as shown in the following equation (Craig, 1971),

$$
M=\left(\frac{k_{r w}}{\mu_{w}}\right)_{S_{o r}}\left(\frac{\mu_{o}}{k_{r o}}\right)_{S_{w i}}
$$

where,

$$
\begin{array}{ll}
M & =\text { mobility ratio } \\
\boldsymbol{k}_{\boldsymbol{r w}} & =\text { relative permeability to water } \\
\mu_{o} & =\text { viscosity of oil } \\
\mu_{w} & =\text { viscosity of water }
\end{array}
$$
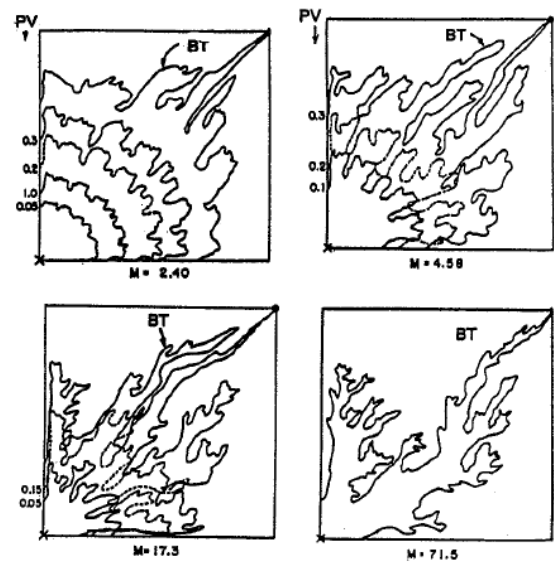
- PRODUCING WEL

PV-PORE VOLUME INJECTED
BT - BREAKTHROUGH

Figure 8 . Viscous fingering at mobility ratios greater than unity.

The mobility ratio is an extremely important parameter in any displacement process. It affects both areal and vertical sweep (particularly in a 3D physical model), with sweep decreasing as $M$ increases for a given volume of fluid injected. Further, $M$ affects the stability of a displacement process, with flow becoming unstable (non-uniform displacement front) when $M>1.0$. This unstable flow is called viscous fingering. Since the value of $M$ for overall displacement processes in this research is about 1.47 , therefore the recovery processes referred to as an unfavorable mobility ratio. That's why the total recovery factor $(\mathrm{RF})$ or overall recovery efficiency $\left(\mathrm{E}_{\mathrm{T}}\right)$ for this research is not too impressive (or moderate recovery factor) due to instability of displacement process and the lack of mobility control that lead to a viscous fingering and early breakthrough during waterflooding and surfactant injection processes. 
Table 4. Oil recovery factor after displacement processes on 3D physical model.

\begin{tabular}{|c|c|c|c|c|c|}
\hline No & $\begin{array}{l}\text { Recovery } \\
\text { Method }\end{array}$ & Technique & $\begin{array}{c}\text { Soaking } \\
\text { Time (Day) }\end{array}$ & $\begin{array}{c}\text { Incremental } \\
(\% \text { OOIP })\end{array}$ & $\begin{array}{l}\text { Total Recovery } \\
\text { Factor (\%OOIP) }\end{array}$ \\
\hline 1 & Waterflooding & $\begin{array}{l}\text { Continuous } \\
\text { Injection }\end{array}$ & - & 25.5 & 25.5 \\
\hline 2 & $\begin{array}{l}\text { Surfactant } \\
\text { Injection }\end{array}$ & $\begin{array}{l}\text { Continuous } \\
\text { Injection }\end{array}$ & - & 5.5 & 31.0 \\
\hline 3 & $\begin{array}{l}\text { Surfactant } \\
\text { Injection }\end{array}$ & $\begin{array}{l}\text { Huff \& Puff } \\
\text { (Stimulation) }\end{array}$ & 1 & 6.8 & 37.8 \\
\hline 4 & $\begin{array}{l}\text { Surfactant } \\
\text { Injection }\end{array}$ & $\begin{array}{l}\text { Huff \& Puff } \\
\text { (Stimulation) }\end{array}$ & 1 & 6.9 & 44.7 \\
\hline 5 & $\begin{array}{l}\text { Surfactant } \\
\text { Injection }\end{array}$ & $\begin{array}{l}\text { Huff \& Puff } \\
\text { (Stimulation) }\end{array}$ & 3.5 & 7 & 51.7 \\
\hline
\end{tabular}

Since surfactant injection is typically improve microscopic displacement efficiency $\left(E_{D}\right)$, we believe that addition of mobility controller injection such as polymer or foam to improve volumetric sweep efficiency $\left(\mathrm{E}_{\mathrm{V}}\right)$ could resolve this problem and finally increase the total oil recovery factor $\left(\mathrm{E}_{\mathrm{T}}\right)$ from $3 \mathrm{D}$ physical model. Nevertheless, the research shows that the combination of continuous surfactant injection alternating huff \& puff stimulation obviously improve the total oil recovery factor to some extent. Hence, we strongly suggest its application on a field based chemical EOR project in the future.

\section{CONCLUSIONS}

1. The secondary recovery by performing $0.17 \mathrm{PV}$ water injection at a rate of 0.273 cc/min brought recovery factor to $25.5 \%$ of OOIP at a watercut of $86.9 \%$. Amount of water injected later did not recover the residual oil effectively due to high capillary and viscosity forces competition.

2. Conventional EOR surfactant injection by injecting chemical continuously assisted by chase waterflood could only recovered the residual oil up to $5.5 \%$ of OOIP which was lesser than expected.

3. The combination between $0.2 \mathrm{PV}$ of continuous EOR surfactant injection with huff \& puff stimulation at injection rate of $0.218 \mathrm{cc} / \mathrm{min}$ with a concentration of $2 \mathrm{wt} \%$ gave significant incremental oil recovery factor and extends the production life.

4. There was a significant effect of surfactant soaking time with the reservoir fluids mobilization and production. The stripping process played an important role in the oil recovery from the physical model.

5. The ultimate oil recovery factor from 3D physical model after performing waterflood, continuous surfactant injection and huff \& puff surfactant stimulation was about 51.7 $\%$ OOIP. This moderate oil recovery factor could be improved by addition of mobility controller injection such as polymer or foam to enhance its volumetric sweep efficiency $\left(\mathrm{E}_{\mathrm{V}}\right)$ which lead to increase of the total oil recovery factor $\left(\mathrm{E}_{\mathrm{T}}\right)$ from the physical model. 


\section{ACKNOWLEDGEMENTS}

We would like to thank everybody who has paid a lot of contributions to make this research possible and institutions (ITSB and ITB) which provided facilities during the experimental study.

\section{REFERENCES}

1) Craig, F. F. Jr. (1971). The Reservoir Engineering Aspects of Waterflooding. Texas: Monograph Series, SPE.

2) Green, D. W and Willhite G. P. (1998). Enhanced Oil Recovery. Texas: Henry L. Doherty Memorial Fund of AIME, SPE.

3) Henthorne L., Hartman M., dan Hayden A. (2011). Improving Chemical EOR Economics by Optimizing Water Quality, SPE 144397 Presented at the SPE Enhanced Oil Recovery Conference Held in Kuala Lumpur, Malaysia, 19-21 July 2011.

4) Hill, H. J., Reisberg, J., Stegemeier, G. L. (1973). Aqueous Surfactant Systems for Oil Recovery. SPE-3798.

5) Pope, G. A.: “The Application of Flow Theory to Enhance Oil Recovery," SPE 7660, Richardson, TX, 1980.

6) Rosen, M. J. (2004). Surfactants and Interfacial Phenomena (Third Edition). New York: John Wiley \& Sons.

7) Skauge, A. and Aanonsen, S. I. 1988. Dynamic Fluid Saturation Profiles in the Analysis of Surfactant Flooding Core Displacement. SPE/DOE-17347.

8) Skauge A. \& Espedal M. (2007). Progress in EOR for Maximising tail Production, CPIR, Norway.

9) Taber, J. J. 1969. Dynamic and Static Forces Required to Remove a Discontinuous Oil Phase from Porous Media Containing Both Oil and Water. SPEJ.

10) Teletzke G. F., Wattenbarger R. C., dan Wilkinson J. R. (2008). Enhanced Oil Recovery Pilot Testing Best Practices, Paper SPE 118055 Presented at the SPE International Petroleum Exhibition and Conference Held in Kuala Abu Dhabi, UAE, 3-6 November 2008.

11) Willhite, G. P. (1986). Waterflooding. Texas: Textbook Series, SPE. 